\title{
Delayed Intrinsic Activation of an NMDA-Independent CaM-kinase II in a Critical Time Window Is Necessary for Late Consolidation of an Associative Memory
}

\author{
Huimin Wan, Beth Mackay, Hassan Iqbal, Souvik Naskar, and György Kemenes \\ Sussex Centre for Neuroscience, School of Biological Sciences, University of Sussex, Falmer, Brighton BN1 9QG, United Kingdom
}

\begin{abstract}
Calcium/calmodulin-dependent kinases (CaM-kinases) are central to various forms of long-term memory (LTM) in a number of evolutionarily diverse organisms. However, it is still largely unknown what contributions specific CaM-kinases make to different phases of the same specific type of memory, such as acquisition, or early, intermediate, and late consolidation of associative LTM after classical conditioning. Here, we investigated the involvement of CaM-kinase II (CaMKII) in different phases of associative LTM induced by single-trial reward classical conditioning in Lymnaea, a well established invertebrate experimental system for studying molecular mechanisms of learning and memory. First, by using a general CaM-kinase inhibitor, KN-62, we found that CaM-kinase activation was necessary for acquisition and late consolidation, but not early or intermediate consolidation or retrieval of LTM. Then, we used Western blot-based phosphorylation assays and treatment with CaMKIINtide to identify CaMKII as the main CaM-kinase, the intrinsic activation of which, in a critical time window ( $\sim 24 \mathrm{~h}$ after learning), is central to late consolidation of LTM. Additionally, using MK-801 and CaMKIINtide we found that acquisition was dependent on both NMDA receptor and CaMKII activation. However, unlike acquisition, CaMKII-dependent late memory consolidation does not require the activation of NMDA receptors. Our new findings support the notion that even apparently stable memory traces may undergo further molecular changes and identify NMDA-independent intrinsic activation of CaMKII as a mechanism underlying this "lingering consolidation." This process may facilitate the preservation of LTM in the face of protein turnover or active molecular processes that underlie forgetting.
\end{abstract}

\section{Introduction}

Calcium/calmodulin-dependent kinases (CaM-kinases) are highly suitable molecular substrates for long-term memory storage due to the unique ability of this group of enzymes to maintain an active autophosphorylated state even after the decay of external stimuli (i.e., when $\mathrm{Ca}^{2+}$ influx stops) (Hook and Means, 2001; Hudmon and Schulman, 2002a). CaMKII, like other CaMkinases, can be activated by transient influx of $\mathrm{Ca}^{2+}$ (e.g., through NMDA receptors) and plays a role in subsequent transcriptional and translational processes involving the cAMP response element binding protein (CREB), a key transcription factor for learning and memory (for review, see Silva et al., 1998; Abel and Lattal, 2001; Cammarota et al., 2002; Hudmon and Schulman, 2002b; Wang et al., 2006).

The involvement of CaMKII in memory acquisition has been well documented (for review, see Cammarota et al., 2002; Silva, 2003; Elgersma et al., 2004). However, the role of, and especially the temporal pattern for, the involvement of CaMKII in memory

Received June 3, 2009; revised Sept. 18, 2009; accepted 0ct. 9, 2009.

This work was supported by the Medical Research Council (UK). H.I. was a recipient of the Wolfson Scholarship Award of the Royal College of Physicians (UK). S.N. was a recipient of a Wellcome VIP Award from the University of Sussex.

Correspondence should be addressed to Prof. G. Kemenes, Sussex Centre for Neuroscience, School of Biological Sciences, University of Sussex, Falmer, Brighton BN1 90G, UK. E-mail: G.Kemenes@sussex.ac.uk.

DOI:10.1523/JNEUROSCI.2577-09.2010

Copyright $\odot 2010$ the authors $\quad 0270-6474 / 10 / 300056-08 \$ 15.00 / 0$ consolidation still remains largely unclear, with only a few studies directly showing that activation of CaMKII is necessary for the consolidation of behavioral long-term memory (Wolfman et al., 1994; Frankland et al., 2001; Miller et al., 2002; Wang et al., 2003; Bevilaqua et al., 2005).

Here, we sought to investigate the temporal involvement of CaMKII in various different stages of associative learning and memory in a single, well defined experimental system. Previous work in the pond snail Lymnaea stagnalis has provided important insights into the molecular mechanisms of associative memory after single-trial classical reward conditioning (for review, see Kemenes, 2008), and here we used the many advantages offered by this system and paradigm to study the role of CaMKII in the acquisition, early, intermediate, and late consolidation and retrieval of long-term associative memory.

Here, for the first time, we identify a critical time window (occurring at $\sim 24 \mathrm{~h}$ after training) during which intrinsic activation of CaMKII is required for late consolidation of associative memory. Additionally, we demonstrate that CaMKII activation is required for memory acquisition, but not for early or intermediate consolidation or memory retrieval. We also show that NMDA receptors are involved in the acquisition but not late consolidation of long-term memory (LTM), indicating a dissociation of NMDA receptor function and CaMKII activation between these two different phases of memory formation. 


\section{Materials and Methods}

Experimental animals. Lymnaea stagnalis pond snails were bred at the University of Sussex. The snails were maintained in large holding tanks using $\mathrm{Cu}^{2+}$-free water (also used throughout the experiments) at $18-20^{\circ} \mathrm{C}$ with a $12 \mathrm{~h}$ light-dark cycle, and fed ad libitum on lettuce and a vegetable-based fish food (TETRA Werke). The animals were fooddeprived for two $\mathrm{d}$ before the beginning of the conditioning procedure.

Single-trial conditioning protocol and pharmacological treatments. A membrane-permeable inhibitor of the activation of CaM-kinases, 1-[N,O-bis(5-isoquinolinesulfonyl)- $N$-methyl-L-tyrosyl]-4-phenylpiperazine (KN-62) (Sigma-Aldrich) was applied to the nervous system of intact animals for the first set of experiments. $\mathrm{KN}-62$ has been shown to inhibit the activation of CaMKII (Davies et al., 2000), but also other CaM-kinases such as CaMKI, CaMKIV, and CaMK kinase (Hidaka and Yokokura, 1996) and thus any effects observed after administering $\mathrm{KN}-62$ can indicate whether or not there is an involvement of at least one of these CaM-kinases in the memory task used. When KN-62 was found to affect memory, we further investigated whether the observed effects were due to the inhibition of the activation of CaMKII. In these experiments we used myristoylated CaMKIINtide (Merck Chemicals), a specific CaMKII inhibitor that is membrane permeable and does not inhibit other CaM-kinases or CaMK kinases (Chang et al., 1998; Pereda et al., 1998; Soderling et al., 2001). We then performed further experiments administering an NMDA receptor blocker MK-801 (Sigma-Aldrich) at time points when inhibiting CaMKII activation resulted in anterograde amnesia. The purpose of this third experiment was to establish whether the involvement of CaMKII in acquisition or consolidation of associative memory is related to the activation of NMDA receptors; CaMKII activation has been linked to NMDA receptor activation in previous studies of both memory and synaptic plasticity (Davis et al., 1992; Giese et al., 1998; Shimizu et al., 2000; Miller et al., 2002; Bevilaqua et al., 2005).

Snails were trained using an established single-trial reward classical conditioning protocol (Alexander et al., 1984; Kemenes et al., 2002). Before training, the snails were placed individually into Petri dishes containing $90 \mathrm{ml}$ of water for a $10 \mathrm{~min}$ acclimatization period, so that a constant low level of spontaneous rasping (stereotyped feeding movements of the mouth) was reached in the novel environment (Kemenes and Benjamin, 1994). Then four types of experiment were performed: "acquisition," "retrieval." "early consolidation," and "intermediate and late consolidation" (Fig. 1). Three groups of animals were used in each type of experiment. To test the effects of general CaM-kinase inhibition on memory, one group was injected in the hemolymph with KN-62 [final concentration $10 \mu \mathrm{M}$ in $0.67 \%$ dimethyl sulfoxide (DMSO, SigmaAldrich)] at different time points: 30 min before memory acquisition (Fig. 1A), $30 \mathrm{~min}$ before retrieval (Fig. 1B), $15 \mathrm{~min}$ after acquisition (Fig. $1 C$ ), or at a range of longer intervals after conditioning, with a further $18 \mathrm{~h}$ allowed before testing (Fig. $1 \mathrm{D}$ ). A second group (Veh) was also trained in each experiment, but in this group the animals were injected with the vehicle (0.67\% DMSO in the hemolymph). Finally, a naive group (not trained or injected) was also used in each experiment to identify baseline responses to the conditioned stimulus (CS). The set up of the groups of snails used in the experiments testing the specific effects of CaMKIINtide and MK-801 was similar to that used in the experiments with $\mathrm{KN}-62$. Three groups were used: the drug-treated group ("Ntide" or "MK-801") was injected with CaMKIINtide (final concentration $4 \mu \mathrm{M}$ in $0.17 \%$ DMSO in the hemolymph) or MK-801 (final concentration $2 \mu \mathrm{M}$ in $0.067 \%$ DMSO in the hemolymph), respectively; the "Veh" group was injected with the vehicle alone, i.e., $0.17 \%$ or $0.067 \%$ DMSO, respectively, and the "Naive" group was neither trained nor injected.

For the CS + unconditioned stimulus (US) paired protocol training, $5 \mathrm{ml}$ of amyl acetate solution $(0.08 \%$ in water, the CS) was delivered into the dish using a plastic syringe and was followed $15 \mathrm{~s}$ later by $5 \mathrm{ml}$ of sucrose solution ( $13.4 \%$ in water, the US). Snails remained in the CS + US mixture for a further $105 \mathrm{~s}$ (thus the total time exposed to stimuli was $2 \mathrm{~min}$ ). After training, snails were placed into a tank of clean water and after 10 min transferred back to their home tanks. For testing, individual snails were taken from their home tanks using a

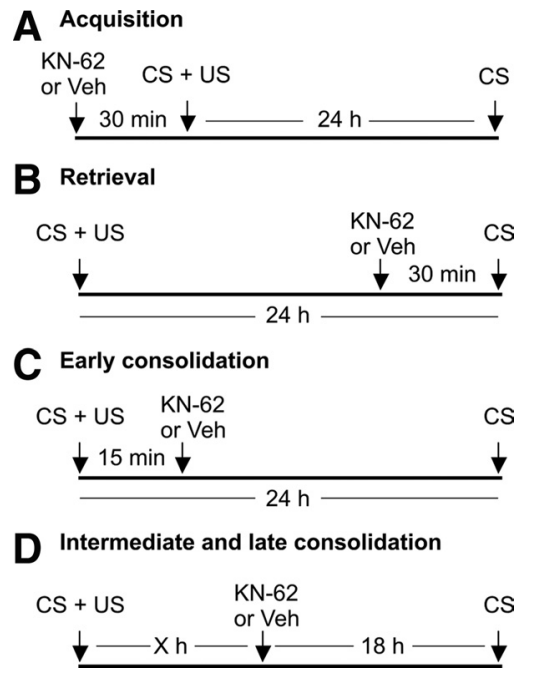

Figure 1. The combinations of training, injection, and memory test regimes used to investigate the role of CaM-kinases in long-term memory after single-trial classical reward conditioning. $\boldsymbol{A}$, To test for a role of CaM-kinase type enzymes in acquisition, $\mathrm{KN}-62$ or vehicle was injected 30 min before training (CS + US) and memory tested $24 \mathrm{~h}$ after training (CS). $\boldsymbol{B}$, To test for a role in retrieval, $\mathrm{KN}-62$ or vehicle was injected 30 min before presenting the $\mathrm{CS}$ at $24 \mathrm{~h}$ after training. C, To test for a role in early consolidation, KN-62 or vehicle was injected 15 min after training and memory was tested $24 \mathrm{~h}$ after training. $D$, To test for a role in intermediate and late consolidation, $\mathrm{KN}-62$ or vehicle was injected at various different time points $(X=6,12,20,24$, or $30 \mathrm{~h}$ ) after training and memory was tested $18 \mathrm{~h}$ later.

blind procedure and placed in Petri dishes. After a 10 min acclimatization period, rasps were counted for 2 min (i.e., spontaneous rasping). $5 \mathrm{ml}$ of the $\mathrm{CS}$ was then applied to the dish, and rasps were counted for a further $2 \mathrm{~min}$ (i.e., the feeding response to the CS). The "feeding score" was defined as the feeding response to the CS minus spontaneous rasping.

Cloning of a partial Lymnaea $\alpha$ CaMKII cDNA sequence. To determine whether a homolog of vertebrate $\alpha$ CaMKII exists in Lymnaea stagnalis, we cloned the functional domains of the autoregulatory region of $\alpha \mathrm{CaMKII}$ in the nervous system of this species. Total RNA samples were isolated from the pooled central ganglia of 10 snails with Absolutely RNA Miniprep Kit (Stratagene) according to the manufacturer's instructions. To synthesize first strand cDNA, reverse transcription (RT) using SuperScript II Rnase Reverse Transcription (Invitrogen) was carried out, according to the manufacturers' instructions, in $20 \mu \mathrm{l}$ of mixture containing $1-5 \mu \mathrm{g}$ of total RNA sample, $1 \mu \mathrm{l}$ of random primer (Roche Diagnostics), $1 \mu$ l of 10 mm dNTP Mix (10 mm each dATP, dGTP, dCTP, dTTP, Roche Diagnostics), $4 \mu \mathrm{l}$ of $5 \times$ First Strand Buffer, and $2 \mu \mathrm{l}$ of $0.1 \mathrm{M}$ DTT (both from Invitrogen), $1 \mu$ l (200 units) of SuperScript II Reverse Transcriptase (Invitrogen), $1 \mu \mathrm{l}$ of RNase inhibitor (Ambion Applied Biosystems), and sterile distilled $\mathrm{H}_{2} \mathrm{O}$. The first strand cDNA produced was then used as a template for PCR amplification. Two pairs of degenerate nested oligonucleotides, directed to the conserved region among the cDNA sequence for human $\alpha$ CaMKII (708-921), were used to amplify the partial $\alpha$ CaMKII sequence of Lymnaea. These were as follows: [5'-GT(GC)GG(AC)TA(CT)CC(AT)TT(CT)TGG3'](forward outside), [5'-TT(CT)TGGGA(CT)GA(AG)GA(CT)GA (AG)C-3'] (forward inside), [5'-CAACAT(GT)GT(GT)GT(GC)AG(AG) AT(AG)GC(GT)CC-3'] (reverse inside), [5'-CGAAA(AG)TT(CT)CT(GT) GT(AG)GC(CT)AACAT-3'] (reverse outside). PCR was performed in a GeneAmp PCR system (PerkinElmer Life and Analytical Sciences), for 40 cycles, denaturing at $95^{\circ} \mathrm{C}$ for $15 \mathrm{~s}$, annealing at $48^{\circ} \mathrm{C}$ for $30 \mathrm{~s}$ and extending at $72^{\circ} \mathrm{C}$ for $30 \mathrm{~s}$ using Hotstar Plus Taq (Giagen). Amplified cDNAs were subcloned into a pCR2.1 vector $(25 \mathrm{ng} / \mu \mathrm{l})$ with TA Cloning Kit (Invitrogen). The ligation products were used to transform TOPO10' cells (Invitrogen). Colonies were selected and plasmid DNA was isolated and analyzed by restriction enzyme EcoRI and purified with Miniprep Kit (Qiagen) and finally was sequenced by MWG-Biotech AG. 
Western blot analysis of pCaMKII levels after classical conditioning. Phosphorylated CaMKII levels were compared among five different groups of animals. One group was trained using the paired CS/US protocol $24.5 \mathrm{~h}$ before dissection. Two further groups were subjected to paired training, then injected with $\mathrm{KN}-62$ or vehicle $24 \mathrm{~h}$ later (in the same concentrations that were used in the behavioral experiments), and dissected 30 min after injection. A fourth group contained animals that were subjected to an explicitly unpaired CS/US protocol (CS/US interval, $1 \mathrm{~h}$ ) and a fifth group consisted of naive animals. Each group contained 5 animals and each experiment was repeated 5 times. Previous work has shown that the cerebral and buccal ganglia of the snail are two major brain regions which are involved in food-reward classical conditioning (Kemenes, 2008), thus these ganglia were dissected and prepared as protein samples for Western blotting. After homogenization in ice-cold Tris lysis buffer (125 mM TRIS, pH 6.8), the samples were put on ice and then centrifuged at $4^{\circ} \mathrm{C}$. Supernatants were removed into a clean tube and were then boiled at $95^{\circ} \mathrm{C}$ for 5 min with $50 \mathrm{~mm}$ Tris, pH 6.8, $2 \%$ (w/v) SDS, $10 \%$ glycerol, $10 \% \beta$-mercaptoethanol (BME), $0.01 \%$ Bromophenol Blue (BFB), $2 \mathrm{~mm}$ $\mathrm{Na}_{3} \mathrm{VO}_{4}, 10 \mathrm{~mm} \mathrm{NaF}, 10 \mathrm{~mm} \mathrm{MgCl}_{2}, 50 \mu \mathrm{M}$ ATP, 8 mм EGTA and 2\% protease inhibitor cocktail (Sigma-Aldrich Company) and then centrifuged at $13,000 \times g$ at $4^{\circ} \mathrm{C}$ to remove debris. Approximately $20 \mu \mathrm{g}$ of each sample was run by SDS-PAGE and blotted according to standard methods. The blotted PVDF membrane was blocked for $1 \mathrm{~h}$ at RT or overnight at $4^{\circ} \mathrm{C}$ in Tris Buffer Saline (TBS) with $0.15 \%$ Tween 20 with $5 \%$ nonfat dry milk. The membrane was incubated for $2 \mathrm{~h}$ at RT or overnight at $4^{\circ} \mathrm{C}$ with either mouse monoclonal IgG anti- $\alpha$ subunit CaM-kinase II, or mouse monoclonal IgG anti-phospho-CaM-kinase II (T286) (both from Millipore) diluted 1:500 in TBS/Tween 20/milk and BSA, then washed in TBS/Tween three times, and incubated for $1 \mathrm{~h}$ at RT with secondary antibody (1:1000 horseradish peroxidase (HRP)-linked anti-mouse IgG antibody, New England Biolabs ) diluted in TBS/Tween 20/milk and BSA. The membrane was then washed in TBS/Tween twice and once in TBS. Protein bands were visualized using enhanced chemiluminescence (Millipore). Control samples were only probed with the secondary antibody and showed no bands. Densitometric analysis was performed using ImageJ.

Statistical analysis. Multiple comparisons were made by one-way ANOVA followed by Tukey's post hoc tests to determine pairwise differences among the groups used in each experiment. Differences were considered significant at $p<0.05$.

\section{Results}

Acquisition, but not retrieval of memory, requires CaM-kinase activation

In the first set of experiments we injected KN-62 into intact snails at different time points, either before CS + US training (for memory acquisition, Fig. $1 A$ ) or postlearning (for memory retrieval, Fig. $1 B$ ) to establish whether or not the activation of any CaMK-type enzyme was involved in these processes. When KN-62 was administered 30 min before training and memory was tested $24 \mathrm{~h}$ after training (Fig. $1 \mathrm{~A}$, acquisition), significant differences were found in the feeding scores among the three groups of snails (Fig. 2A). The significantly higher level of feeding responses to the CS in the vehicle-injected trained group (Veh) versus the Naive group (Fig. $2 \mathrm{~A}$ ) indicated that the single-trial classical conditioning was successful. The KN-62-injected trained group showed a significantly lower score than the Veh group, and was not significantly different from the Naive group (Fig. 2A). This indicates that administration of $\mathrm{KN}-62$ prevents the increase in feeding response to the CS that is normally ac-
B
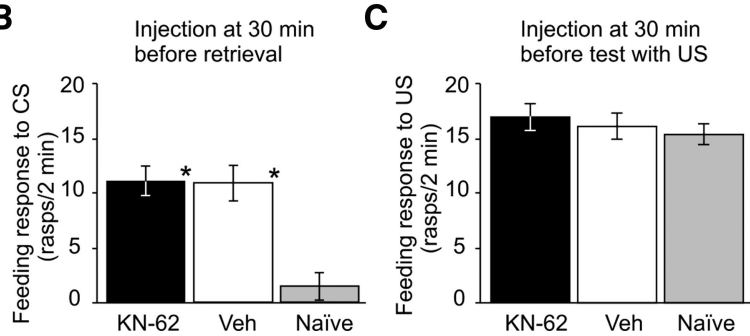

Figure 2. Comparison of the role of the activation of CaM-kinases in the acquisition and retrieval of long-term memory V Vehicle]: $p>0.05)$. C The feeding response to the US was not affected by injection of KN-62 30 min before testing $(n=18,21$ and 19 for the KN-62, Vehicle and Naive groups, respectively). Test statistics: ANOVA: $F_{(2,55)}=2.1, p>0.05$ (n.s.). Asterisks in $\boldsymbol{A}$ through $C$ indicate statistically significant pairwise differences (Tukey's test: $p<0.05$ ) compared to the Naive group data. Error

quired during training, and further implies that the blocking of the activation of CaM-kinases by KN-62 at around the time of training causes impairment to the animals' long-term memory tested at $24 \mathrm{~h}$ after training.

In contrast, there was no significant difference between the $\mathrm{KN}-62$ and Veh groups when animals were injected $30 \mathrm{~min}$ before the CS test at $24 \mathrm{~h}$ after training (Figs. $1 \mathrm{~B}$, retrieval, $2 \mathrm{~B}$ ). Both groups were able to remember what they had learned $24 \mathrm{~h}$ earlier, as shown by a significant increase in feeding response to the CS compared to the Naive group (Fig. $2 \mathrm{~B}$ ). In an additional experiment we found that 30 min after injection with $\mathrm{KN}-62$, the animals' ability to respond to their unconditioned food stimulus, sucrose, was not affected (Fig. 2C). Thus, blocking the activation of CaM-kinases with KN-62 30 min before a food stimulus did not interfere with the animals' ability to produce either the conditioned or unconditioned feeding response. This is in sharp contrast to the strong amnestic effect seen when KN-62 was injected 30 min before training. These results demonstrate that the blocking of the activation of CaM-kinases produces impairment in memory acquisition, but not in memory retrieval, implying that there are different roles for the activation of CaM-kinases in these two fundamental processes of memory.

\section{A distinct critical time window of intrinsic CaM-kinase activation is required for late memory consolidation}

Systemic injection of KN-62 at 15 min (Fig. 1C, early consolidation) or 6,12 or $20 \mathrm{~h}$ after training (Fig. $1 D$, intermediate consolidation) did not cause loss of long-term memory (Fig. 3A, $B$, left panel); the feeding responses of $\mathrm{KN}-62$-injected trained animals were elevated compared to those of naive animals, and indistinguishable from the trained group injected with the vehicle alone. However, injection of KN-62 at $24 \mathrm{~h}$ after training (Fig. $1 \mathrm{D}$, late consolidation) produced a significant reduction of the feeding response tested $18 \mathrm{~h}$ later (Fig. $3 \mathrm{~B}$, middle panel). This impairment of memory was quantitatively similar to the effects seen when KN-62 was injected 30 min before single-trial classical conditioning to block training-induced CaM-kinase activation (Fig. 2 A). As KN-62 injected at $24 \mathrm{~h}$ after training caused amnesia in the apparent absence of any external stimuli, we conclude that $\mathrm{KN}-62$ at this late posttraining time point acts by preventing intrinsically triggered activation of a CaM-kinase type enzyme. Together, the above results suggest that at around the $20 \mathrm{~h}$ point after training, memory seems to be consolidated without a require- 
A

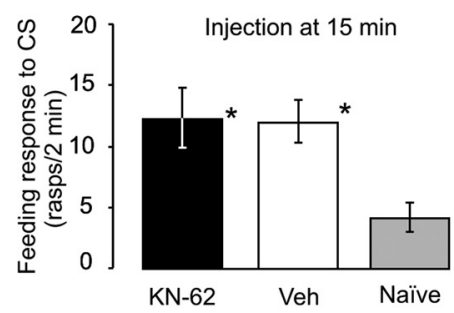

B

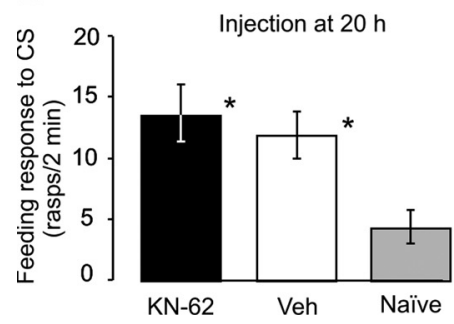

Injection at $6 \mathrm{~h}$

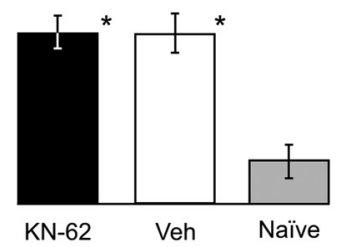

Injection at $24 \mathrm{~h}$

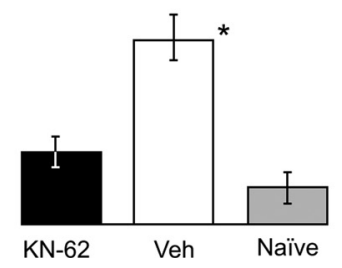

Figure 3. CaM-kinase activation is involved in late consolidation of memory during a distinct time window, but not in early or intermediate consolidation. $\boldsymbol{A}$, Injection of KN-62 $15 \mathrm{~min}, 6$ or $12 \mathrm{~h}$ after training does not lead to impaired long-term memory. Test statistics: ANOVAs: $15 \mathrm{~min}, F_{(2,78)}=33.43, p<0.001 ; 6 \mathrm{~h}, F_{(2,103)}=12.70, p<0.001 ; 12 \mathrm{~h}, F_{(2,50)}=5.74, p<0.01$. Tukey's tests (all 3 experiments): KN-62 versus Vehicle, $p>0.05$ (n.s.). $\boldsymbol{B}$, Middle panel, Injection of KN-62 $24 \mathrm{~h}$ after training causes amnesia 18h later. Test statistics: ANOVA: $F_{(2,91)}=11.22, p<0.001$; Tukey's test (KN-62 versus Vehicle): $p<0.01 . \boldsymbol{B}$, Left and right panels, Injection of KN-62 20 or $30 \mathrm{~h}$ after training does not lead to impaired long-term memory. Test statistics: ANOVAs: $20 \mathrm{~h}, F_{(2,64)}=$ $4.78, p<0.05 ; 30 \mathrm{~h}, F_{(2,85)}=11.58, p<0.01$. Tukey's tests (both experiments): KN-62 versus Vehicle, $p>0.05$ (n.s.). Asterisks in $\boldsymbol{A}$ and $\boldsymbol{B}$ indicate statistically significant responses (Tukey's tests, $p<0.05$ ) compared to the Naive group data.

ment for ongoing activation of CaM-kinases. However, at $\sim 24 \mathrm{~h}$ after training, there is a period where one or more CaM-kinases must become activated in order for associative memory to undergo a late consolidation process.

To determine whether this late consolidation process required a continued activation of a CaM-kinase type enzyme, KN-62 was injected at $30 \mathrm{~h}$ after training and memory was tested $18 \mathrm{~h}$ later (Fig. 1D). In this experiment, the increase in feeding response to the test CS was preserved (Fig. $3 B$, right panel). Thus, a requirement for intrinsic activation of a CaM-kinase type enzyme during late memory consolidation appears to exist in a time window between 20 and $30 \mathrm{~h}$ after training.

Identification of CaMKII as the main CaM-kinase involved in memory acquisition and late consolidation

CaMKII has been postulated as one of the most likely molecular substrates for LTM (Hook and Means, 2001; Hudmon and Schulman, 2002a). We therefore investigated whether the observed memory impairments by KN-62 resulted from the inhibition of this specific CaM-kinase during memory acquisition, and in particular when KN-62 was applied during the late consolidation phase.

We first confirmed the existence of a bona fide CaMKII in the Lymnaea CNS by cloning the core domains of the autoregulatory region of LymCaMKII, including the autophosphorylation domain (GenBank Accession Number: EF428260). The cloned sections are highly conserved ( $86 \%$ sequence homology with the mammalian $\alpha$ subtype of CaMKII) (Fig. 4) suggesting functional homology and justifying the use of inhibitors and antibodies originally developed against mammalian CaMKII.

To address the possible role of CaMKII as an important CaMkinase involved in late memory consolidation, the main focus of this paper, we tested whether CaMKII actually showed intrinsic phosphorylation at $24 \mathrm{~h}$ after training. Five replicate experiments
Injection at $12 \mathrm{~h}$
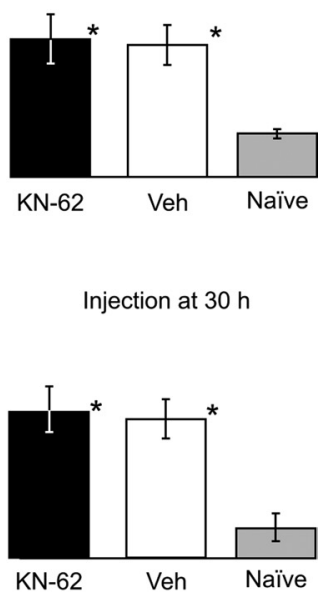

Injection at $30 \mathrm{~h}$

were conducted using the Western blotting technique (see Materials and Methods). In these experiments we also tested whether, if such phosphorylation occurred, it could be prevented by treatment with KN-62, the broad-spectrum CaMkinase inhibitor used in the behavioral experiments. These experiments showed that, relative to total CaMKII levels, there was a significantly higher level of phosphorylated CaMKII present in the buccal and cerebral ganglia at $\sim 24 \mathrm{~h}$ after contingent training (CS/US interval, $30 \mathrm{~s}$ ) than in naive and explicitly unpaired control animals (CS/US interval, $1 \mathrm{~h}$ ). Importantly, the same experiments also showed that the increased phosphorylation induced by contingent training was significantly blocked by KN-62 (Fig. 5A,B). The biochemical findings at $\sim 24 \mathrm{~h}$ after training (Fig. 5B) corresponded strongly with the results of behavioral tests conducted $18 \mathrm{~h}$ later on groups of trained and control animals in the same experiment (Fig. 5C). These results both demonstrate that CaMKII is activated $\sim 24 \mathrm{~h}$ after training and suggest that the activation of this specific CaM-kinase is necessary for the consolidation of associative memory.

In the next set of experiments, we tested whether inhibition of CaMKII alone was sufficient to lead to the significant memory impairments seen in the experiments where KN-62 was used. In these tests we used CaMKIINtide, a specific inhibitor of CaMKII (Chang et al., 1998). The application of this drug $30 \mathrm{~min}$ before training significantly impaired the snails' performance at the memory test $24 \mathrm{~h}$ after training (Fig. 6A), indicating that the inhibition of CaMKII alone is capable of impairing acquisition of associative memory. The impairment caused by the administration of CaMKIINtide is quantitatively similar to that produced by the administration of KN-62 (compare Fig. $6 A$ and Fig. $2 A$ ), demonstrating that the effects observed in the experiments using KN-62 (injected $30 \mathrm{~min}$ before training) were mainly due to the inhibition of CaMKII activation. This experiment therefore provides specific evidence for the important role of CaMKII in this stage of LTM.

More crucially, administration of CaMKIINtide $24 \mathrm{~h}$ after training also significantly reduced the conditioned feeding score of the CaMKIINtide-treated animals compared with the vehicletreated animals when they were tested $18 \mathrm{~h}$ after injection (Fig. $6 B)$. The effects caused by the administration of CaMKIINtide were again similar to those produced by $\mathrm{KN}-62$ in the same time window (compare Fig. $6 B$ and Fig. $3 B$, middle panel). This demonstrates further that the effects observed in the experiment using KN-62 (injected $24 \mathrm{~h}$ after training) were due specifically to the inhibition CaMKII activation at $\sim 1 \mathrm{~d}$ after training. These results, together with the results of the Western blot experiments, provide the first experimental evidence to show definitively that CaMKII plays a crucial role in late consolidation of LTM after single-trial classical food-reward conditioning in Lymnaea.

CaMKIINtide recently has been shown to inhibit both calcium-dependent CaMKII activity and the autonomously active kinase itself (Vest et al., 2007). It was therefore also important to test the effect of CaMKIINtide at a time point after training when KN-62 had no effect, such as $20 \mathrm{~h}$ after training (see Fig. 3), 


\section{Lymnaea VGYPPFWDEDQHRLYAQIKAGAYDYPSPEWDTVTPEAKNLINSMLTVNPAKRINASEALK 60 Human VGYPPFWDEQHRLYQQIKAGAYDFPSPEWDTVTPEAKDLINKMLTINPSKRITAAEALK 60}

Lymnaea HPWICQRERVASVVHRQETVDCLKKFNARRKLKGAILTTML 101

Human HPWISHRSTVASCMHRQETVDCLKKFNARRKLKGAILTTML 101

Figure 4. Amino acid (AA) sequence predicted from the partially cloned Lymnaea $\alpha$ CaMKII cDNA and the corresponding AA sequence of human $\alpha$ CaMKII. The homology of these sequences between the two species is $86 \%$. The cloned region contains the $\alpha$ CaMKII autoregulatory (including autophosphorylation) domain (Lymnaea position 89-101) and part of the catalytic domain (position 1-88). Asterisks indicate identical amino acids in the Lymnaea and human sequences.

to distinguish between these two mechanisms. A significant amnestic effect arising from treatment with CaMKIINtide at this time point would indicate that this peptide inhibitor impairs memory after single-trial conditioning in Lymnaea mainly by blocking autonomously active CaMKII. On the other hand, a lack of amnestic effect in response to CaMKIINtide treatment at $20 \mathrm{~h}$ after training would suggest that the amnesia observed at $24 \mathrm{~h}$ after training in both the KN-62 and CaMKIINtide experiments resulted from an inhibition of calcium-dependent intrinsic activation of CaMKII.

When we injected CaMKIINtide into a group of animals $20 \mathrm{~h}$ after training, these animals showed no memory impairment $18 \mathrm{~h}$ later compared to a vehicle-injected trained group ( $n=22$ for each group). Both groups showed significantly higher levels of feeding response to the CS (7.0 \pm 2.1 and $7.2 \pm 2.2 \mathrm{bites} / 2 \mathrm{~min}$, respectively) compared to a Naive control group $(n=20,2.0 \pm 1.2 \mathrm{bites} / 2 \mathrm{~min}$; ANOVA, $F_{(2,63)}=4.7, p<0.01$; Tukey's, $\left.p<0.05\right)$ and they were not significantly different from one another (Tukey's, $p>0.05$ ). The findings from this experiment lend strong support to the notion that, similar to $\mathrm{KN}-62$, the amnestic responses to CaMKIINtide treatment at $24 \mathrm{~h}$ after training are due to its inhibitory effect on calcium-dependent kinase activity rather than on autonomously active CaMKII.

\section{NMDA receptors are involved in}

CaMKII-dependent acquisition,

but not late consolidation, of associative memory

Previous work in other systems has demonstrated a direct link between NMDA receptors and activation of CaMKII (Bayer et al., 2001), and recently, NMDA-like receptors have been characterized at the molecular level in both Aplysia and Lymnaea (Ha et al., 2006). Moreover, glutamate has been shown to be an important transmitter in the Lymnaea feeding system (Brierley et al., 1997; Hatakeyama et al., 2007). The effects of glutamate on neurons of the feeding network have been shown to be modulated by nitric oxide (D'yakonova and D'yakonova, 2008), a transmitter necessary for memory consolidation after single-trial learning in Lymnaea (Kemenes et al., 2002). Importantly, a close link between
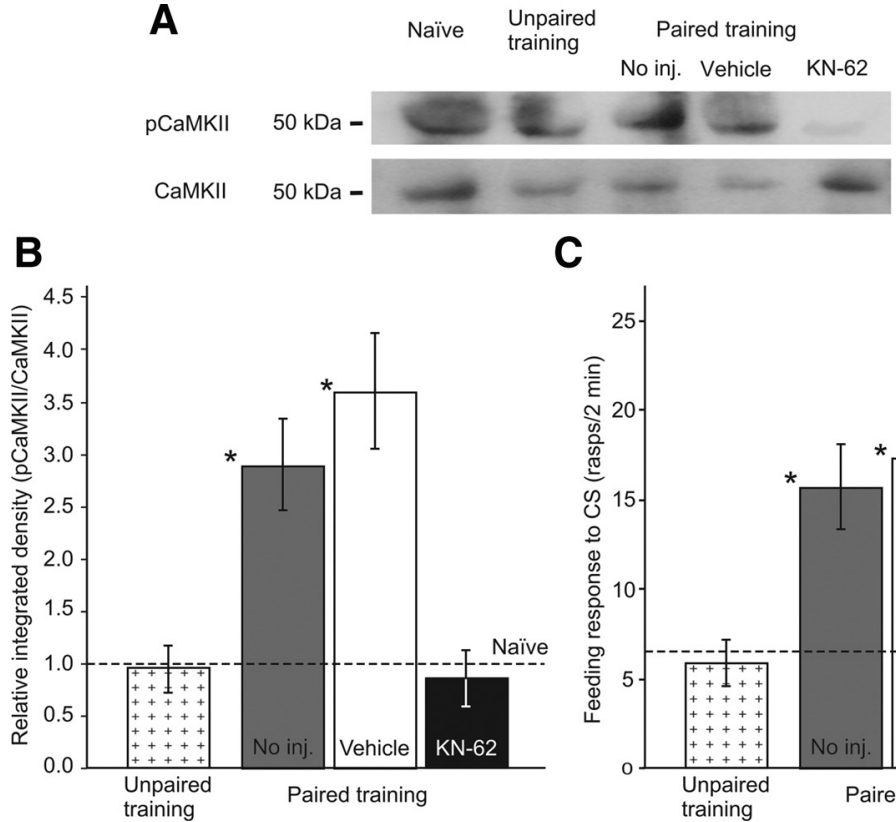

C

Figure 5. Increased intrinsic phosphorylation of CaMKII $24 \mathrm{~h}$ after single-trial classical reward conditioning and late memory consolidation. $\boldsymbol{A}, \boldsymbol{B}$, Western blot experiments. Three main experimental groups were used, one injected with KN-62 $24 \mathrm{~h}$ after paired training, one injected with vehicle and one uninjected. Cerebral and buccal ganglia were dissected from all trained animals at $24.5 \mathrm{~h}$ after training and also from animals of an unpaired control group and a naive control group. Homogenates from five replicates of five pooled tissue samples per group (see Materials and Methods) were loaded onto gels and the resulting blots probed with either a pCaMKII antibody (example in $\boldsymbol{A}$, top) or with a total CaMKII antibody (example in $\boldsymbol{A}$, bottom). The total CaMKII signal was used as an internal standard for densitometric comparisons. Relative integrated density values (pCaMKII/CaMKII) in samples taken from naive animals were assigned a value of 1 . All other relative integrated density values were normalized to this naive baseline (dashed line) and used for multiple statistical comparisons (shown in $\boldsymbol{B}$, significance compared to Unpaired group indicated by asterisks). Test statistics: ANOVA: $F_{(3,19)}=11.2, p<0.003$; Tukey's tests: No inj. (paired) versus Unpaired, $p<0.05$; Vehicle (paired) versus Unpaired, $p<0.01 ; \mathrm{KN}-62$ (paired) versus № inj. (paired) and Vehicle (paired), $p<0.05$ and 0.01 , respectively; KN-62 (paired) versus Unpaired, $p>0.05$ (n.s.), No. inj. (paired) versus Vehicle (paired), $p>0.05$ (n.s.). C, Memory tests. Three groups of trained (paired stimulus) animals from the experiment described in $\boldsymbol{A}$ and $\boldsymbol{B}$ were kept for behavioral tests performed $18 \mathrm{~h}$ after injection. Naive and unpaired control animals from the same experiment were also saved for behavioral tests. Note that for an easier comparison with the densitometric data in B, for the Naive group, only the mean value is shown (dashed line; SE \pm 1.6$)$. Test statistics: ANOVA: $F_{(4,138)}=6.6, p<0.0001$; Tukey's tests: No inj. (paired) versus Unpaired and Naive, $p<0.01$ and 0.05, respectively; Vehicle (paired) versus Unpaired and Naive, $p<0.01$ and 0.05, respectively; KN-62 (paired) versus No inj. (paired) and Vehicle (paired), $p<0.05 ; \mathrm{KN}-62$ (paired) versus Unpaired and Naive, $p>0.05$ (n.s.); No. inj. (paired) versus Vehicle (paired), $p>0.05$ (n.s.). Significance compared to unpaired group is indicated by asterisks.

NMDA receptor function and CaMKII activation has been found in various different forms of synaptic plasticity and learning and memory (Izquierdo et al., 1999; Moriya et al., 2000; Bevilaqua et al., 2005; Sakurai et al., 2007). As part of our analysis of the evolutionarily conserved role of CaMKII in LTM in Lymnaea, we tested whether a similar link between NMDA receptor and CaMKII activation played a role in different phases of memory formation in this mollusc. We were particularly interested in finding out whether or not the activation of NMDA receptors and CaMKII together played a role in late consolidation as suggested by recent experiments using knock-out mice, leading to the for- 

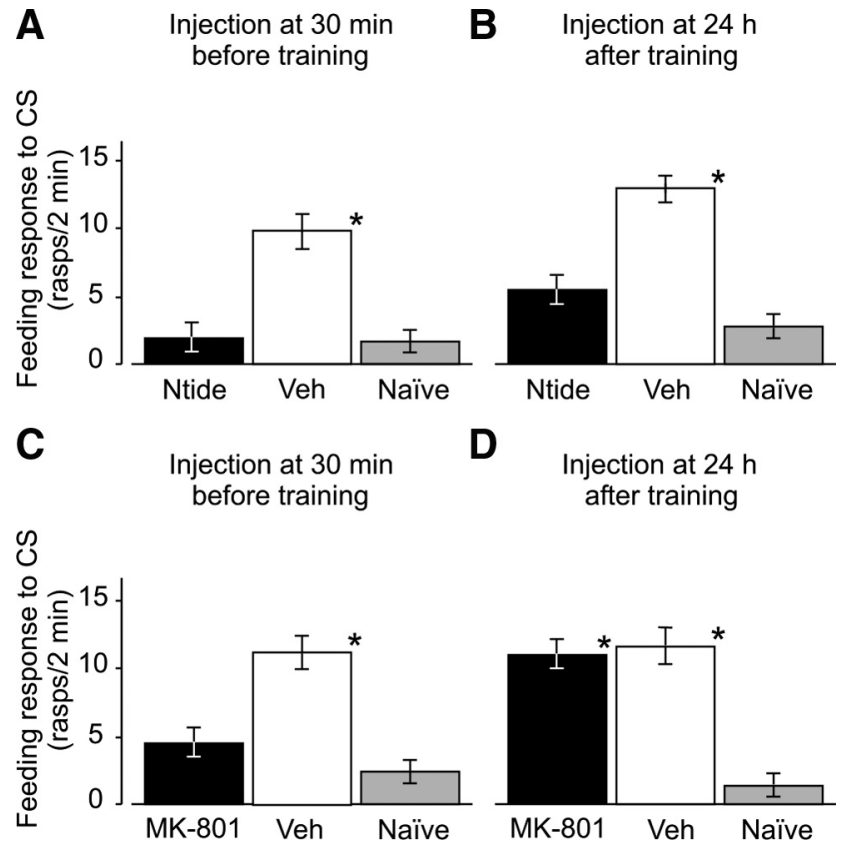

Figure 6. Dissociation of the role of NMDA receptor and CaMKII activity in different phases of memory formation after single-trial classical conditioning. $A, B$, CaMKIl is necessary during both acquisition (injection at $30 \mathrm{~min}$ before training) and late consolidation (injection at $24 \mathrm{~h}$ after training) of associative memory. Test statistics: $A$, ANOVA: $F_{(2,64)}=6.80, p<0.01$; Tukey's test (CaMKIINtide vs Vehicle): $p<0.05 ; \boldsymbol{B}$, ANOVA: $F_{(2,69)}=8.28, p<0.001$; Tukey's test (CaMKIINtide vs Vehicle): $p<0.05$. C, $\boldsymbol{D}$, Activation of NMDA receptors is only necessary for acquisition but not late consolidation of associative memory. Test statistics: C, ANOVA: $F_{(2,67)}=5.70, p<0.01$; Tukey's test (MK-801 vs Vehicle): $p<0.05$; D, ANOVA: $F_{(2,66)}=6.4, p<0.01$; Tukey's test (MK-801 vs Vehicle): $p>0.05$ (n.s.). Significance compared to naive group is indicated by asterisks.

mulation of the synaptic reentry reinforcement hypothesis for memory consolidation (Wang et al., 2006).

Similar to both KN-62 and CaMKIINtide, administration of the general NMDA receptor inhibitor MK-801 at $30 \mathrm{~min}$ before training significantly reduced the animals' conditioned feeding score when tested $24 \mathrm{~h}$ after training (Fig. 6C). This result demonstrates, for the first time, the role played by NMDA-like receptors in the acquisition of LTM in Lymnaea and indicates a close correlation between activation of CaMKII and activation of NMDA receptors, similar to that shown in other systems (Davis et al., 1992; Giese et al., 1998; Shimizu et al., 2000; Bevilaqua et al., 2005). However, when MK-801 was injected $24 \mathrm{~h}$ after training and the animals were tested $18 \mathrm{~h}$ after injection, no significant difference was found between the MK-801-treated and vehicletreated groups (Fig. 6D) (ANOVA, $F_{(2,138)}=14.39, p<0.001$; Tukey's (MK-801 versus Veh), $p>0.05)$. Both these groups performed significantly better than the naive group (Fig. 6D) (Tukey's, $p<0.05$ ), indicating that administration of MK-801 $24 \mathrm{~h}$ after training did not affect LTM tested $18 \mathrm{~h}$ after injection. These results, in contrast to those found when MK-801 was injected 30 min before training and tested $24 \mathrm{~h}$ after training, indicate a dissociation between the activation of CaMKII and the activation of NMDA receptors, suggesting that the intrinsic activation of CaMKII $24 \mathrm{~h}$ after training is NMDA-independent.

\section{Discussion}

Here, we show first that activation of CaMKII, a major subtype of the CaM-kinases, is required for the acquisition of long-term associative memory in Lymnaea. Furthermore, we show that activation of NMDA receptors is also crucial for acquisition of this type of classical conditioning. This finding is consistent with the vertebrate learning literature (Silva et al., 1992; Davis et al., 1992; Giese et al., 1998; Shimizu et al., 2000; Rodrigues et al., 2004; Irvine et al., 2005; Bevilaqua et al., 2005), implying that the role of CaMKII and its close correlation with the activation of NMDA receptors in learning is conserved between invertebrates and vertebrates. NMDA-like receptors are present in both Aplysia and Lymnaea (Ha et al., 2006), providing a molecular foundation for functional conservation.

Importantly, we have identified for the first time a distinct critical time window ( $\sim 24 \mathrm{~h}$ after training) during which intrinsic activation of CaMKII occurs and CaMKII is specifically required for late consolidation of associative memory. Moreover, in contrast to its role in acquisition and late consolidation, we found no evidence for a role of the activation of CaMKII (or other CaM-kinases) in early or intermediate consolidation, for up to $20 \mathrm{~h}$ after training.

Both KN-62 and CaMKIINtide affect the interaction between the $\mathrm{Ca}^{2+} / \mathrm{CaM}$ complex by directly binding to the CaM-binding site of CaMKII. However, KN-62, unlike CaMKIINtide, does not affect the $\mathrm{Ca}^{2+} / \mathrm{CaM}$-independent activity of the already autophosphorylated (activated) enzyme (Tokumitsu et al., 1990; Vest et al., 2007). Thus, both of these drugs inhibit functions that require fresh activation of CaMKII, but in addition, CaMKIINtide may also act by inhibiting autonomously active CaMKII (Vest et al., 2007). The $20 \mathrm{~h}$ posttraining treatment with either KN-62 or CaMKIINtide was equally ineffective at producing amnesia, showing that neither fresh activation of CaM kinases nor autonomous activity of CaMKII are necessary for memory maintenance or late consolidation at this time point. However, the possibility remains that autonomous CaMKII activity plays a functional role in certain other phases of memory. Further studies are necessary to examine this possibility, for example by measuring the level of autophosphorylated CaMKII at different phases of memory acquisition, consolidation, or at the time of memory retrieval.

As treatment with KN-62 and CaMKIINtide at $24 \mathrm{~h}$ after training caused loss of memory at a much later time point, we conclude that an ongoing activation of CaMKII occurs at $\sim 24 \mathrm{~h}$ and that this plays a crucial role in a distinct late memory consolidation process. Indeed, CaMKII activation may signal the beginning of this late consolidation phase. This observation suggests the interesting possibility that similar to mammalian systems, there is a late process of synaptic reentry reinforcement in Lymnaea, which is dependent on the reactivation of CaMKII and is necessary for the long-term storage of old memories (Wang et al., 2003). Whether or not this also indicates the existence of systems level memory consolidation in Lymnaea, which follows the previously described molecular consolidation processes taking place between 0 and $6 \mathrm{~h}$ after training (Kemenes, 2008), remains to be investigated.

We also established that unlike during acquisition, the activation of CaMKII at $\sim 24 \mathrm{~h}$ after training is not dependent upon the activation of NMDA receptors. This finding is also different from what has been described in NMDA receptor and CaMKII knockout mice, where it was suggested that during memory consolidation activation of CaMKII results from the upstream activation of NMDA receptors (Wang et al., 2003). The question arises then: what triggers the intrinsic activation of CaMKII in the Lymnaea CNS if not an NMDA-dependent mechanism? This question may be answered in part by the recent finding that single-trial classical reward conditioning leads to a delayed somal membrane potential depolarization in identified modulatory neurons [the Cere- 
bral Giant Cells (CGCs)] of the Lymnaea CNS, which plays a key role in long-term memory (I. Kemenes et al., 2006). This depolarization emerges between 20 and $24 \mathrm{~h}$ after training, and it is sufficient to lead to a prolonged increase in $\mathrm{Ca}^{2+}$ levels in proximal CGC axon terminals, which in turn is involved in the enhanced response to the CS that occurs after learning (I. Kemenes et al., 2006). A learning-induced delayed rise in $\mathrm{Ca}^{2+}$ levels may well account for the delayed activation of CaMKII involved in late consolidation of memory; our experiments have shown that the time windows for these two events coincide (between $\sim 20$ and $24 \mathrm{~h}$ after training). The exact cellular mechanisms of the depolarization-induced rise in $\mathrm{Ca}^{2+}$ levels in the CGCs are as yet unknown. As the behavioral pharmacological experiments with MK-801 suggested that this rise is not mediated by NMDA receptors, it is likely to be based on the activation of non-NMDA type voltage-gated calcium channels or intracellular calcium stores in the CGC axon terminals, as proposed previously by I. Kemenes et al. (2006).

CaMKII seems to play a distinct but complementary role to other identified signaling molecules in the processes of memory consolidation in Lymnaea. CaMKII is not involved in consolidation $\sim 15$ min after learning, but nitric oxide (NO) and protein kinase A (PKA) are (Kemenes et al., 2002; Michel et al., 2008). However, NO and PKA are not required for late memory consolidation at $\sim 24 \mathrm{~h}$ after training (Kemenes et al., 2002; G. Kemenes, 2006; Michel et al., 2008). The complementary roles played by CaMKII and these other molecules also suggest that the consolidation process is dynamic, and may involve both parallel and sequential activation of different signaling cascades in different phases of the consolidation of long-term memory even after a single training trial.

The delayed intrinsic activation of CaMKII shown here also strongly supports the notion of "lingering consolidation" (Dudai and Eisenberg, 2004). This dynamic feature can be a general characteristic of the memory consolidation process and supports the hypothesis that even a long time after learning, memory may be considered to be consolidated with respect to certain molecules, but not to others.

Our finding that there is no requirement for the activation of CaMKII for memory consolidation $>30 \mathrm{~h}$ after training also supports the general idea of dynamically organized time windows for the posttraining activation of different signaling cascades (Schwärzel and Müller, 2006). It is possible that activation of CaMKII at $\sim 24 \mathrm{~h}$ after training leads to a sustained high level of autophosphorylated CaMKII, and this is required for memory to be maintained in the even longer term [for up to 3 weeks (Alexander et al., 1984)]. However, it is yet to be shown that autophosphorylation of CaMKII in the Lymnaea CNS lasts long enough for this maintained effect and we cannot rule out either that there is recurrent intrinsic activation of CaMKII or other signaling molecules at even later stages of memory, as suggested by the synaptic reentry reinforcement hypothesis formulated in mammalian models of memory consolidation (Wang et al., 2003).

By cloning the functional domains of CaMKII in Lymnaea, we have directly demonstrated the existence of this ubiquitous and crucial molecule in this well established molluscan model system of learning and memory. Our behavioral results demonstrate not only that CaMKII exists in Lymnaea, but also that it shares with its mammalian counterpart important functional roles in learning and memory. Therefore, our findings further strengthen the comparability of the results obtained from invertebrate and vertebrate systems, implicating that there are important conserved molecular mechanisms that underlie fundamental cognitive tasks such as associative learning and memory. Most importantly, however, our work identified a novel NMDA-independent role for CaMKII in late memory consolidation and it has yet to be established whether or not this function too has been conserved in evolutionarily more advanced organisms.

\section{References}

Abel T, Lattal KM (2001) Molecular mechanisms of memory acquisition, consolidation and retrieval. Curr Opin Neurobiol 11:180-187.

Alexander J Jr, Audesirk TE, Audesirk GJ (1984) One-trial reward learning in the snail Lymnaea stagnalis. J Neurobiol 15:67-72.

Bayer KU, De Koninck P, Leonard AS, Hell JW, Schulman H (2001) Interaction with the NMDA receptor locks CaMKII in an active conformation. Nature 411:801-805.

Bevilaqua LR, Medina JH, Izquierdo I, Cammarota M (2005) Memory consolidation induces N-methyl-D-aspartic acid-receptor- and $\mathrm{Ca} 2+1$ calmodulin-dependent protein kinase II-dependent modifications in $\alpha$-amino-3-hydroxy-5-methylisoxazole-4-propionic acid receptor properties. Neuroscience 136:397-403.

Brierley MJ, Yeoman MS, Benjamin PR (1997) Glutamate is the transmitter for $\mathrm{N} 2 \mathrm{v}$ retraction phase interneurons of the Lymnaea feeding system. J Neurophysiol 78:3408-3414.

Cammarota M, Bevilaqua LR, Viola H, Kerr DS, Reichmann B, Teixeira V, Bulla M, Izquierdo I, Medina JH (2002) Participation of CaMKII in neuronal plasticity and memory formation. Cell Mol Neurobiol 22:259-267.

Chang BH, Mukherji S, Soderling TR (1998) Characterization of a calmodulin kinase II inhibitor protein in brain. Proc Natl Acad Sci U S A 95:10890-10895.

Davies SP, Reddy H, Caivano M, Cohen P (2000) Specificity and mechanism of action of some commonly used protein kinase inhibitors. Biochem J 351:95-105.

Davis S, Butcher SP, Morris RG (1992) The NMDA receptor antagonist D-2-amino-5-phosphonopentanoate (D-AP5) impairs spatial learning and LTP in vivo at intracerebral concentrations comparable to those that block LTP in vitro. J Neurosci 12:21-34.

Dudai Y, Eisenberg M (2004) Rites of passage of the engram: reconsolidation and the lingering consolidation hypothesis. Neuron 44:93-100.

D'yakonova TL, D'yakonova VE (2008) Modification of the effects of glutamate by nitric oxide (NO) in a pattern-generating network. Neurosci Behav Physiol 38:407-413.

Elgersma Y, Sweatt JD, Giese KP (2004) Mouse genetic approaches to investigating calcium/calmodulin-dependent protein kinase II function in plasticity and cognition. J Neurosci 24:8410-8415.

Frankland PW, O’Brien C, Ohno M, Kirkwood A, Silva AJ (2001) $\alpha$-CaMKII-dependent plasticity in the cortex is required for permanent memory. Nature 411:309-313.

Giese KP, Fedorov NB, Filipkowski RK, Silva AJ (1998) Autophosphorylation at Thr286 of the $\alpha$ calcium-calmodulin kinase II in LTP and learning. Science 279:870-873.

Ha TJ, Kohn AB, Bobkova YV, Moroz LL (2006) Molecular characterization of NMDA-like receptors in Aplysia and Lymnaea: relevance to memory mechanisms. Biol Bull 210:255-270.

Hatakeyama D, Aonuma H, Ito E, Elekes K (2007) Localization of glutamate-like immunoreactive neurons in the central and peripheral nervous system of the adult and developing pond snail, Lymnaea stagnalis. Biol Bull 213:172-186.

Hidaka H, Yokokura H (1996) Molecular and cellular pharmacology of a calcium/calmodulin-dependent protein kinase II (CaM-kinase II) inhibitor, KN-62, and proposal of CaM-kinase phosphorylation cascades. Adv Pharmacol 36:193-219.

Hook SS, Means AR (2001) Ca(2+)/CaM-dependent kinases: from activation to function. Annu Rev Pharmacol Toxicol 41:471-505.

Hudmon A, Schulman H (2002a) Structure-function of the multifunctional $\mathrm{Ca} 2+/$ calmodulin-dependent protein kinase II. Biochem J 364:593-611.

Hudmon A, Schulman H (2002b) Neuronal Ca2+/calmodulin-dependent protein kinase II: the role of structure and autoregulation in cellular function. Annu Rev Biochem 71:473-510.

Irvine EE, Vernon J, Giese KP (2005) $\alpha$ CaMKII autophosphorylation contributes to rapid learning but is not necessary for memory. Nat Neurosci 8:411-412.

Izquierdo I, Schröder N, Netto CA, Medina JH (1999) Novelty causes time- 
dependent retrograde amnesia for one-trial avoidance in rats through NMDA receptor- and CaMKII-dependent mechanisms in the hippocampus. Eur J Neurosci 11:3323-3328.

Kemenes G (2008) Molecular mechanism of associative learning in Lymnaea. In: Learning and memory: a comprehensive reference (Byrne J, ed), Vol 4, Molecular mechanism of memory (Sweatt JD, ed), pp 133-148. Oxford: Elsevier.

Kemenes G, Benjamin PR (1994) Training in a novel environment improves the appetitive learning performance of the snail, Lymnaea stagnalis. Behav Neural Biol 61:139-149.

Kemenes G, Kemenes I, Michel M, Papp A, Müller U (2006) Phasedependent molecular requirements for memory reconsolidation: differential roles for protein synthesis and protein kinase A activity. J Neurosci 26:6298-6302.

Kemenes I, Kemenes G, Andrew RJ, Benjamin PR, O’Shea M (2002) Critical time-window for NO-cGMP-dependent long-term memory formation after one-trial appetitive conditioning. J Neurosci 22:1414-1425.

Kemenes I, Straub VA, Nikitin ES, Staras K, O'Shea M, Kemenes G, Benjamin PR (2006) Role of delayed nonsynaptic neuronal plasticity in long-term associative memory. Curr Biol 16:1269-1279.

Michel M, Kemenes I, Müller U, Kemenes G (2008) Different phases of long-term memory require distinct temporal patterns of PKA activity after single-trial classical conditioning. Learn Mem 15:694-702.

Miller S, Yasuda M, Coats JK, Jones Y, Martone ME, Mayford M (2002) Disruption of dendritic translation of CaMKII $\alpha$ impairs stabilization of synaptic plasticity and memory consolidation. Neuron 36:507-519.

Moriya T, Kouzu Y, Shibata S, Kadotani H, Fukunaga K, Miyamoto E, Yoshioka T (2000) Close linkage between calcium/calmodulin kinase II alpha/beta and NMDA-2A receptors in the lateral amygdala and significance for retrieval of auditory fear conditioning. Eur J Neurosci 12: 3307-3314.

Pereda AE, Bell TD, Chang BH, Czernik AJ, Nairn AC, Soderling TR, Faber DS (1998) Ca2+/calmodulin-dependent kinase II mediates simultaneous enhancement of gap-junctional conductance and glutamatergic transmission. Proc Natl Acad Sci U S A 95:13272-13277.

Rodrigues SM, Farb CR, Bauer EP, LeDoux JE, Schafe GE (2004) Pavlovian fear conditioning regulates Thr286 autophosphorylation of $\mathrm{Ca} 2+/$ calmodulin-dependent protein kinase II at lateral amygdala synapses. J Neurosci 24:3281-3288.
Sakurai S, Yu L, Tan SE (2007) Roles of hippocampal N-methyl-D-aspartate receptors and calcium/calmodulin-dependent protein kinase II in amphetamine-produced conditioned place preference in rats. Behav Pharmacol 18:497-506.

Schwärzel M, Müller U (2006) Dynamic memory networks: dissecting molecular mechanisms underlying associative memory in the temporal domain. Cell Mol Life Sci 63:989-998.

Shimizu E, Tang YP, Rampon C, Tsien JZ (2000) NMDA receptordependent synaptic reinforcement as a crucial process for memory consolidation. Science 290:1170-1174.

Silva AJ (2003) Molecular and cellular cognitive studies of the role of synaptic plasticity in memory. J Neurobiol 54:224-237.

Silva AJ, Paylor R, Wehner JM, Tonegawa S (1992) Impaired spatial learning in alpha-calcium-calmodulin kinase II mutant mice. Science 257:206-211.

Silva AJ, Kogan JH, Frankland PW, Kida S (1998) CREB and memory. Annu Rev Neurosci 21:127-148.

Soderling TR, Chang B, Brickey D (2001) Cellular signaling through multifunctional Ca2+/calmodulin-dependent protein kinase II. J Biol Chem 276:3719-3722.

Tokumitsu H, Chijiwa T, Hagiwara M, Mizutani A, Terasawa M, Hidaka H (1990) KN-62, 1-[N,O-bis(5-isoquinolinesulfonyl)-N-methyl-L-tyrosyl]4-phenylpiperazine, a specific inhibitor of $\mathrm{Ca} 2+/$ calmodulin-dependent protein kinase II. J Biol Chem 265:4315-4320.

Vest RS, Davies KD, O'Leary H, Port JD, Bayer KU (2007) Dual mechanism of a natural CaMKII inhibitor. Mol Biol Cell 18:5024-5033.

Wang H, Shimizu E, Tang YP, Cho M, Kyin M, Zuo W, Robinson DA, Alaimo PJ, Zhang C, Morimoto H, Zhuo M, Feng R, Shokat KM, Tsien JZ (2003) Inducible protein knockout reveals temporal requirement of CaMKII reactivation for memory consolidation in the brain. Proc Natl Acad Sci U S A 100:4287-4292.

Wang H, Hu Y, Tsien JZ (2006) Molecular and systems mechanisms of memory consolidation and storage. Prog Neurobiol 79:123-135.

Wolfman C, Fin C, Dias M, Bianchin M, Da Silva RC, Schmitz PK, Medina JH, Izquierdo I (1994) Intrahippocampal or intraamygdala infusion of KN62, a specific inhibitor of calcium/calmodulin-dependent protein kinase II, causes retrograde amnesia in the rat. Behav Neural Biol 61:203205. 